\title{
Risk Factors for Abdominal Wound Dehiscence in Children: A Case-Control Study
}

\author{
Gabriëlle H. van Ramshorst • Nathalie E. Salu • \\ Nikolaas M. A. Bax · Wim C. J. Hop · Ernst van Heurn · \\ Daniel C. Aronson · Johan F. Lange
}

Published online: 7 May 2009

(c) The Author(s) 2009. This article is published with open access at Springerlink.com

\begin{abstract}
Background In the limited literature concerning abdominal wound dehiscence after laparotomy in children, reported incidences range between $0.2-1.2 \%$ with associated mortality rates of $8-45 \%$. The goal of this retrospective case-control study was to identify major risk factors for abdominal wound dehiscence in the pediatric population.

Methods Patients younger than aged 18 years who developed abdominal wound dehiscence in three pediatric surgical centers during the period 1985-2005 were
\end{abstract}

G. H. van Ramshorst $(\square)$ · N. E. Salu · J. F. Lange

Department of Surgery, Erasmus University Medical Center,

Room Z-836, P.O. Box 2040, 3000 CA Rotterdam,

The Netherlands

e-mail: g.vanramshorst@erasmusmc.nl

N. M. A. Bax

Department of Pediatric Surgery, Erasmus University Medical Center-Sophia, 3000 CB Rotterdam, Rotterdam,

The Netherlands

W. C. J. Hop

Department of Biostatistics, Erasmus University Medical Center, 3000 CA Rotterdam, The Netherlands

E. van Heurn

Department of Surgery, Academic Hospital Maastricht, 6202 AZ Maastricht, The Netherlands

D. C. Aronson

Pediatric Surgical Center of Amsterdam, Emma Children's Hospital AMC and Vrije Universiteit Medical Center,

Amsterdam, The Netherlands

Present Address:

D. C. Aronson

Radboud University Medical Center, 6500 HB Nijmegen,

The Netherlands identified. For each patient with abdominal wound dehiscence, four controls were selected by systematic random sampling. Patients with (a history of) open abdomen treatment or abdominal wound dehiscence were excluded as control subjects. Putative relevant patient-related, operation-related, and postoperative variables for both cases and control subjects were evaluated in univariate analyses and subsequently entered in multivariate stepwise logistic regression models to identify major independent predictors of abdominal wound dehiscence.

Results A total number of 63 patients with abdominal wound dehiscence and 252 control subjects were analyzed. Mean presentation of abdominal wound dehiscence was at postoperative day 5 (range, 1-15) and overall mortality was $11 \%$. Hospital stay was significantly longer $(p<0.001)$ in the case group (median, 42 vs. 10 days). Major independent risk factors for abdominal wound dehiscence were younger than aged 1 year, wound infection, median incision, and emergency surgery. Incisional hernia was reported in $12 \%$ of the patients with abdominal wound dehiscence versus $3 \%$ in the control group $(p=0.001)$.

Conclusions Abdominal wound dehiscence is a serious complication with high morbidity and mortality. Median incisions should be avoided whenever possible.

\section{Introduction}

Abdominal wound dehiscence is a severe complication of abdominal surgery in children. Its sudden presentation and requirement of surgical repair in the majority of cases underline the stressful character of this complication for both patients and parents. Literature on risk factors for abdominal wound dehiscence in children is limited 
Table 1 Literature concerning abdominal wound dehiscence in children

\begin{tabular}{llllll}
\hline Author & Year of publication & No. of patients & Incidence (\%) & Mortality (\%) & Statistical analyses \\
\hline Gross and Furguson [1] & 1953 & 75 & 0.9 & 45.3 & NR \\
Campbell and Swenson [2] & 1972 & 26 & 0.97 & 19.2 & NR \\
Gruessner et al. [3] & 1986 & 21 & 1.17 & 14.3 & NR \\
Waldhausen and Davies [4] & 2000 & 12 & 0.43 & 8.3 & Univariate \\
Çigdem et al. [5] & 2006 & 27 & 0.08 & 34.5 & Univariate \\
Van Ramshorst $^{\mathrm{a}}$ & 2009 & 63 & 0.6 & 11.1 & Multivariate \\
\hline
\end{tabular}

$N R$ not reported

${ }^{a}$ Current series

(Table 1). Reported incidences range from 0.4-1.2\%, with mortality rates reported as high as 45\% [1-5]. Until now, only relatively small case series, series without control groups, or without multivariate logistic regression analyses have been reported, which complicates interpretation of the results of these studies [1-5].

In the study by Waldhausen and Davies, vertical incision was reported as a risk factor (compared with transverse incision) [4]. Based on the characteristics of his population, he concluded that abdominal wound dehiscence is more frequent in young children (younger than aged 1 year). Age (younger than 1 month) and median incision also have been reported as risk factors by Çigdem et al. [5]. The outcomes of these reports should be considered relative due to the minority of variables studied. This case-control study was designed to evaluate a substantial number of possible risk factors for abdominal wound dehiscence in children through univariate analyses and multivariate stepwise logistic regression.

\section{Materials and methods}

All patient charts, office notes, and operation records of patients younger than aged 18 years from three pediatric surgical centers who had been treated between January 1985 through December 2005 were found by use of a computer-generated search, using the keywords "dehiscence," "wound dehiscence," "fascial dehiscence," and "Platzbauch." Patients who primarily underwent laparoscopic surgery, abdominal surgery in other departments (e.g., pediatric urology), umbilical, and inguinal hernia surgery were excluded. Identified patients were excluded if insufficient evidence of abdominal wound dehiscence was found in the patient charts.

For each case, four control patients at the same center who had been operated in the same week were selected. If the number of controls was too small during that week, patients from the succeeding week(s) were selected as controls as well. Controls were not matched according to age or type of surgery, because these variables were considered putative risk factors and we intended to assess their effects. Patients with (a history of) open abdomen treatment or abdominal wound dehiscence were excluded as control subjects.

The following variables were collected for all cases and controls: age, sex, weight, body mass index, duration of pregnancy (in case of neonates), anemia, hypoalbuminemia, hypoproteinemia, uremia, diabetes mellitus, malignancy, jaundice, pulmonary disease, use of corticosteroids, (parental) smoking, sepsis, ascites, previous laparotomy, type of surgery, indication for surgery, duration of surgery, emergency or elective operation, hemodynamic instability, ASA-classification, type of incision, method of closure, suture material used, day of presentation, cause of abdominal wound dehiscence, postoperative coughing/ vomiting/wound infection, hospital stay, in-hospital mortality, and incisional hernia.

On the condition that at least $85 \%$ of data were complete, patients with abdominal wound dehiscence were compared with controls using the $\chi^{2}$ or Mann Whitney $U$ test for categorical or continuous data, respectively. Subsequently, all factors that were significant in univariate analyses were entered in multivariate stepwise logistic regression with backwards elimination to identify major independent predictors of abdominal wound dehiscence. Odds ratios (OR) and regression coefficients were calculated for all variables. $P<0.05$ was considered significant.

\section{Results}

A total of 63 patients with abdominal wound dehiscence and 252 control subjects were analyzed. The incidence of abdominal wound dehiscence could be calculated from hospital records for one of the pediatric surgical centers and was found to be $0.6 \%$ (12/1,942 patients). The mean presentation of abdominal wound dehiscence was at 
postoperative day 5 (range, 1-15). In most cases, tearing of sutures through the fascia was reported to be the cause of the dehiscence (29\%). Other reported causes were infection $(13 \%)$ or a combination of infection and fascial tearing $(3 \%)$, broken sutures $(10 \%)$, and loose knots $(5 \%)$. In the remaining 26 patients, no explanation was recorded.

Hospital stay was significantly longer $(p<0.001)$ for patients with abdominal wound dehiscence with a median of 42 days versus 10 days for controls. In-hospital mortality was $11 \%$ and $6 \%$, respectively $(p=0.151)$. Patients who died in the hospital were significantly younger ( $p=0.021)$ and suffered more frequently from necrotizing enterocolitis compared with survivors $(23 \%$ vs. $4 \%$, $p<0.001)$. No recurrences of abdominal wound dehiscence were found. One patient developed abdominal wound dehiscence twice after laparotomies in separate hospital admissions 1 year apart. In $13 \%$ of the patients with abdominal wound dehiscence (7/56 survivors), incisional hernia was reported in medical records after the initial admission compared with $3 \%$ (6/237 survivors) in the control group ( $p=0.001)$.

Data were incomplete in more than $15 \%$ of patients for preoperative protein and albumin levels, uraemia, duration of pregnancy, (birth) weight, (parental) smoking, body mass index, hemodynamic instability, ASA-classification, type of suture, and suture technique, which prevented us from entering these factors in univariate analyses. The techniques of fascial closure (running vs. interrupted, multilayered vs. mass-closure) could not be extracted from original operation records in $40 \%$ of patients with abdominal wound dehiscence and in $43 \%$ of patients in the control group.

The results of the univariate analyses are shown in Table 2. The distributions of the following variables differed significantly between patients with and without abdominal wound dehiscence: age, anemia, jaundice, malignancy, type of incision, type of surgery, emergency surgery, necrotizing enterocolitis, hypertrophic pyloric stenosis, and wound infection. The variables sex, previous laparotomy, diabetes mellitus, pulmonary disease, corticosteroid use, sepsis, ascites, duration of operation, postoperative coughing, and vomiting, were not found to be significant risk factors.

All factors that were significant in univariate analyses were subsequently entered in multivariate stepwise logistic regression with backwards elimination to determine which variables were significant independent risk factors (Table 3). In the evaluation of "type of surgery," the subgroup "abdominal wall" was expected to be associated with the lowest risk of abdominal wound dehiscence, including "clean" procedures, e.g., incisional hernia repairs and exploratory laparotomies. Therefore, this category was chosen as reference category. For the variable "age", the reference category consisted of children older than 1 year in view of group sizes. There was no significant difference between children younger than aged 6 weeks compared with those aged between 6 weeks and 1 year. In view of small group sizes, incisions other than median incisions (McBurney, transverse, and semilunar incisions) were combined to form one category to assess the effects of median incisions.

In multivariate analyses age up to 1 year, wound infection, median incision, and emergency surgery proved independent risk factors. Adjusted for these significant risk factors, none of the other variables had significant effects.

\section{Discussion}

We have been able to investigate the second-largest population of pediatric patients with abdominal wound dehiscence reported in literature so far, covering a period of 20 years. The substantial size of the control group has enabled thorough analyses of variables to identify major independent risk factors for abdominal wound dehiscence. The severity of this complication is illustrated by the associated morbidity and mortality as described in this article.

In this study, wound infections were found in $24 \%$ of patients with abdominal wound dehiscence and in $7 \%$ of patients in the control group. Although these rates may seem to be high, similar data have been reported in literature. In previous studies on abdominal wound dehiscence, Campbell et al. reported that a deep wound infection preceded $23 \%$ of the dehisced wounds [2]. Finally, Çigdem et al. observed significant wound infection before development of abdominal evisceration in $27.5 \%$ [5]. Sharma and Sharma reported an overall wound infection rate of $5.43 \%$ in a series of 1,325 consecutive patients operated in a general pediatric surgery unit [6]. In these series, wound infection rates were $12.39 \%$ in children undergoing colonic surgery and rates of $13.75 \%$ in neonates.

Very young age has been associated with suboptimal wound healing in many studies. Impaired or immature wound healing and higher risks to develop wound infection explain the increased risk of developing abdominal wound dehiscence in children younger than aged 1 year [6-10]. Necrotizing enterocolitis is highly prevalent in this age group and is without exception combined with poor clinical condition and emergency surgery, which again negatively influence wound healing. Decreased breaking strengths of abdominal incisions, combined with increased abdominal pressure due to ileus or mechanical ventilation put a patient at risk for abdominal wound dehiscence.

Median incisions, in these series of patients, can be associated with an increased risk for abdominal wound dehiscence. Although there have been some reports of 
Table 2 Results of univariate analyses

\begin{tabular}{|c|c|c|c|c|c|}
\hline \multirow{3}{*}{$\begin{array}{l}\text { Variable } \\
\text { Age (year) median } \pm \mathrm{SD} \text {, range }\end{array}$} & \multicolumn{4}{|c|}{ No. of patients $(\%)$} & \multirow{3}{*}{$\begin{array}{l}P \text { value } \\
<0.001^{\mathrm{a}}\end{array}$} \\
\hline & \multicolumn{2}{|c|}{ Abdominal wound dehiscence group $(n=63)$} & \multicolumn{2}{|c|}{ Control group $(n=252)$} & \\
\hline & $0.2 \pm 3.9$ & (2-17.4 days) & $1.1 \pm 5.5$ & (0-17.7 days) & \\
\hline 0-6 weeks & 19 & $30 \%$ & 52 & $21 \%$ & \\
\hline 6 weeks-1 year & 35 & $56 \%$ & 71 & $28 \%$ & \\
\hline$>1$ year & 9 & $14 \%$ & 129 & $51 \%$ & \\
\hline Male/female ratio & $38 / 25$ & $60 \% / 40 \%$ & $142 / 110$ & $56 \% / 44 \%$ & 0.569 \\
\hline Diabetes mellitus & 0 & $0 \%$ & 2 & $1 \%$ & 0.639 \\
\hline Pulmonary disease & 11 & $18 \%$ & 31 & $12 \%$ & 0.281 \\
\hline Corticosteroid use & 3 & $5 \%$ & 12 & $5 \%$ & 0.649 \\
\hline Malignancy & 1 & $2 \%$ & 25 & $10 \%$ & 0.032 \\
\hline Ascites & 5 & $8 \%$ & 15 & $6 \%$ & 0.563 \\
\hline Previous laparotomy & 10 & $16 \%$ & 61 & $24 \%$ & 0.157 \\
\hline Anemia & 19 & $30 \%$ & 75 & $30 \%$ & 0.829 \\
\hline Jaundice & 13 & $21 \%$ & 14 & $6 \%$ & $<0.001$ \\
\hline Sepsis & 9 & $14 \%$ & 17 & $7 \%$ & 0.052 \\
\hline Necrotizing enterocolitis & 9 & $14 \%$ & 7 & $3 \%$ & $<0.001$ \\
\hline Hypertrophic pyloric stenosis & 16 & $25 \%$ & 25 & $10 \%$ & 0.001 \\
\hline Emergency surgery & 42 & $67 \%$ & 124 & $50 \%$ & 0.013 \\
\hline Type of surgery & & & & & $0.015^{\mathrm{a}}$ \\
\hline Abdominal wall & 13 & $21 \%$ & 65 & $26 \%$ & \\
\hline Stomach-pylorus & 16 & $25 \%$ & 29 & $12 \%$ & \\
\hline Small bowel & 14 & $22 \%$ & 29 & $12 \%$ & \\
\hline Large bowel & 16 & $25 \%$ & 94 & $37 \%$ & \\
\hline Gall bladder/bile duct/liver & 3 & $5 \%$ & 12 & $5 \%$ & \\
\hline Kidney/adrenal gland & 1 & $2 \%$ & 20 & $8 \%$ & \\
\hline Other $^{\mathrm{b}}$ & 0 & $0 \%$ & 3 & $1 \%$ & \\
\hline Type of incision & & & & & $0.002^{\mathrm{a}}$ \\
\hline Transverse & 36 & $57 \%$ & 101 & $40 \%$ & \\
\hline Midline & 15 & $24 \%$ & 38 & $15 \%$ & \\
\hline Semilunar (umbilical) & 5 & $8 \%$ & 14 & $6 \%$ & \\
\hline Subcostal & 2 & $3 \%$ & 14 & $6 \%$ & \\
\hline McBurney & 0 & $0 \%$ & 50 & $20 \%$ & \\
\hline Lumbotomy & 0 & $0 \%$ & 2 & $1 \%$ & \\
\hline Unknown & 5 & $8 \%$ & 33 & $13 \%$ & \\
\hline Operation time $(\mathrm{min})$, median $\pm \mathrm{SD}$ & $65 \pm 103$ & $(20-600)$ & $75 \pm 83$ & $(15-550)$ & 0.665 \\
\hline Coughing & 3 & $5 \%$ & 7 & $3 \%$ & 0.425 \\
\hline Vomiting & 5 & $8 \%$ & 17 & $7 \%$ & 0.782 \\
\hline Wound infection & 15 & $24 \%$ & 18 & $7 \%$ & $<0.001$ \\
\hline
\end{tabular}

${ }^{a}$ Overall $p$ value

b Other: 2 splenectomies, 1 vascular procedure

median incisions as a risk factor for abdominal wound dehiscence [2, 4, 11, 12], a number of authors have not been able to confirm this in previous studies [13-17]. However, transverse incisions are preferred to median incisions by the majority of pediatric surgeons, largely because of the strong association between median incisions and incisional hernia in the literature.
Aforementioned variables also have been reported as risk factors in adult patient series. Apparently, similar mechanisms are responsible for the development of abdominal wound dehiscence in both children and adults. Although the surgical technical aspect of abdominal wound dehiscence has not been the focus of this report, the importance of technique should not be ignored. In adults, 
Table 3 Results of multivariate stepwise logistic regression analyses

\begin{tabular}{|c|c|c|c|c|}
\hline \multirow[t]{2}{*}{ Risk factor } & \multirow{2}{*}{$\begin{array}{l}\text { Odds ratio } \\
(\mathrm{OR})\end{array}$} & \multicolumn{2}{|c|}{$95 \% \mathrm{CI}$ for $\mathrm{OR}$} & \multirow[t]{2}{*}{$p$ value } \\
\hline & & Lower limit & Upper limit & \\
\hline Age up to 1 year $^{\mathrm{a}}$ & 9.5 & 4.03 & 22.36 & $<0.001$ \\
\hline Wound infection & 3.7 & 1.46 & 9.17 & 0.006 \\
\hline Median incision $^{\mathrm{b}}$ & 2.9 & 1.29 & 6.74 & 0.01 \\
\hline Emergency surgery & 2.8 & 1.37 & 5.54 & 0.01 \\
\hline
\end{tabular}

${ }^{a}$ Reference category age over 1 year

b reference category other types of incisions (McBurney, transverse, etc.)

the use of slowly resorbable suture material in a continuous suturing method has been accepted as the "gold standard" $[18,19]$. In pediatric surgery, however, multifilament material, such as polyglactin is still widely used. Possibly, the use of slowly resorbable suture material has less support among pediatric surgeons due to the low incidence of incisional hernia in the pediatric population. The influence of, for example, suture length to wound length ratio and tissue bite size on tissue breaking strength and the development of incisional hernia and abdominal wound dehiscence has not yet been investigated in children. For patients (both children and adults) with increased risks to develop abdominal wound dehiscence, these factors deserve more attention in future research and clinical practice.

We have studied a large number of putative risk factors for abdominal wound dehiscence in a large population of pediatric patients. For the first time, multivariate regression analyses were performed to identify major independent risk factors. Abdominal wound dehiscence has proven a serious complication, associated with high morbidity and mortality. Risk factors for abdominal wound dehiscence include patient age younger than 1 year, wound infection, median incision, and emergency surgery. Two of these factors can be mitigated by pediatric surgeons: wound infection and median incision. In view of this, measures against wound infection ought to be stimulated and median incisions should be avoided whenever possible to prevent abdominal wound dehiscence.

Acknowledgments The authors are grateful for the support provided by secretaries of the involved departments and employees of the Central Medical Archives of Erasmus Medical Center, Pediatric Surgical Center Amsterdam, and Academic Hospital Maastricht by retrieving patient data.
Open Access This article is distributed under the terms of the Creative Commons Attribution Noncommercial License which permits any noncommercial use, distribution, and reproduction in any medium, provided the original author(s) and source are credited.

\section{References}

1. Gross RE, Furguson CL (1953) Abdominal incision in infants and children. Ann Surg 137:349-355

2. Campbell DP, Swenson O (1972) Wound dehiscence in infants and children. J Ped Surg 7:123-126

3. Gruessner R, Pistor G, Kotei DN et al (1986) Relaparotomie im Kindesalter. Langenbecks Arch Chir 367:167-180

4. Waldhausen JHT, Davies L (2000) Pediatric postoperative abdominal wound dehiscence: transverse versus vertical incisions. J Am Col Surg 190:688-691

5. Çigdem MK, Onen A, Otçu S et al (2006) Postoperative abdominal evisceration in children: possible risk factors. Pediatr Surg Int 22:677-680

6. Sharma LK, Sharma PK (1986) Postoperative wound infection in a pediatric surgical service. J Pediatr Surg 21:889-891

7. Carr R (2000) Neutrophil production and function in newborn infants. Br J Haematol 110:18-28

8. Haeney M (1994) Infection determinants at extremes of age. J Antimicrob Chemother 34(Suppl A):1-9

9. Quie PG (1990) Antimicrobial defenses in the neonate. Semin Perinatol 14(4 Suppl 1):2-9

10. Fleer A, Gerards LJ, Verhoef J (1988) Host defence to bacterial infection in the neonate. J Hosp Infect 11(Suppl A):320-327

11. Keill RH, Ford Keitzer WF, Kirt Nichols WK et al (1973) Abdominal wound dehiscence. Arch Surg 106:573-577

12. Halasz NA (1968) Dehiscence of laparotomy wounds. Am J Surg 116:210-214

13. Riou JPA, Cohen JR, Johnson H (1992) Factors influencing wound dehiscence. Am J Surg 163:324-330

14. Gislason H, Gronbeck JE, Soreide O (1995) Burst abdomen and incisional hernia after major gastrointestinal operations-comparison of three closure techniques. Eur J Surg 161:349-354

15. Irvin TT, Vassilakis S, Chattopadhyay DK et al (1978) Abdominal wound healing in jaundiced patients. Br J Surg 65:521-522

16. Armstrong CP, Dixon JM, Duffy SW (1984) Wound healing in obstructive jaundice. Br J Surg 71:267-270

17. Greenall MJ, Evans M, Pollock AV (1980) Midline or transverse laparotomy? A random controlled clinical trial. Part I: Influence on healing. Br J Surg 67:188-190

18. Van 't Riet M, Steyerberg EW, Nellensteyn J et al (2002) Metaanalysis of techniques for closure of midline abdominal incisions. Br J Surg 89:1350-1356

19. Hodgson NC, Malthaner RA, Ostbye T (2000) The search for an ideal method of abdominal fascial closure: a meta-analysis. Ann Surg 231:436-442 